\title{
Does good leadership buffer effects of high emotional demands at work on risk of antidepressant treatment? A prospective study from two Nordic countries
}

\author{
Ida E. H. Madsen • Linda L. Magnusson Hanson • \\ Reiner Rugulies • Töres Theorell · Hermann Burr • \\ Finn Diderichsen $\cdot$ Hugo Westerlund
}

Received: 20 December 2012/ Accepted: 3 February 2014/Published online: 20 February 2014

(C) The Author(s) 2014. This article is published with open access at Springerlink.com

\begin{abstract}
Purpose Emotionally demanding work has been associated with increased risk of common mental disorders. Because emotional demands may not be preventable in certain occupations, the identification of workplace factors that can modify this association is vital. This article examines whether effects of emotional demands on antidepressant treatment, as an indicator of common mental disorders, are buffered by good leadership.

Methods We used data from two nationally representative work environment studies, the Danish Work Environment Cohort Study $(n=6,096)$ and the Swedish Longitudinal Occupational Survey of Health $(n=3,411)$, which were merged with national registers on antidepressant purchases. All individuals with poor self-reported baseline mental health or antidepressant purchases within 8.7 months before baseline were excluded, and data
\end{abstract}

I. E. H. Madsen $(\bowtie) \cdot$ R. Rugulies

The National Research Centre for the Working Environment, Lerso Park Allé 105, 2100 Copenhagen, Denmark

e-mail: ihm@nrcwe.dk

\section{L. M. Hanson - T. Theorell · H. Westerlund}

Stress Research Institute, Stockholm University, Stockholm, Sweden

R. Rugulies · F. Diderichsen

Department of Public Health, University of Copenhagen, Copenhagen, Denmark

\section{R. Rugulies}

Department of Psychology, University of Copenhagen,

Copenhagen, Denmark

H. Burr

Federal Institute of Occupational Safety and Health, Berlin, Germany analysed prospectively. Using Cox regression, we examined hazard ratios (HRs) for antidepressants in relation to the joint effects of emotional demands and leadership quality. Buffering was assessed with Rothman's synergy index. Cohort-specific risk estimates were pooled by random effects meta-analysis.

Results High emotional demands at work were associated with antidepressant treatment whether quality of leadership was poor $(\mathrm{HR}=1.84,95 \%$ CI 1.32-2.57) or good $(\mathrm{HR}=1.70,95 \% \mathrm{CI} 1.25-2.31)$. The synergy index was 0.66 (95\% CI 0.34-1.28).

Conclusions Our findings suggest that good leadership does not substantially ameliorate any effects of emotional demands at work on employee mental health. Further research is needed to identify possible preventive measures for this work environment exposure.

Keywords Work - Stress $\cdot$ Mental health $\cdot$ Common mental disorder $\cdot$ Depression

\section{Introduction}

Common mental disorders such as depression and anxiety are highly prevalent, and a leading cause of disease burden [1]. The causes of common mental disorder are thought to involve a complex interplay of social, psychological, and biological factors [2], and numerous studies have shown associations between psychosocial work environment factors and common mental disorder, particularly depression [3-8].

Emotional demands at work, i.e. aspects of the job that require sustained emotional effort [9], have been associated poor mental health outcomes, including psychological distress $[10,11]$ and depressive symptoms $[12,13]$. Studies 
have also shown associations between emotional demands and indicators of clinically significant common mental disorders, such as hospitalisation with depression [14] and antidepressant treatment [15, 16]. Employees in human service work, such as health care, education, and social work have high emotional demands [15]. In these jobs, emotional demands are thought to stem, among other factors, from particular characteristics of the work, such as confrontation with the problems and suffering of patients and clients [17] - the needs of whom is the central focus of the work [18]. Hence, some types of work might be inherently emotionally demanding, and emotional demands may in these jobs not be amenable to change. It is, therefore, pivotal to examine whether the effects of emotional demands on ill-health can be buffered by other factors, which are modifiable.

The conservation of resources theory states that negative emotional outcomes may occur when resources that an individual values are threatened or lost [19]. Emotional demands at work may result in prolonged expenditure of emotional resources or energy, as they are aspects of the job that require sustained emotional effort [9]. According to conservation of resources theory, the availability of resources determines the impact of resource loss [19]. The theory further states that acknowledgement of accomplishments and tasks and understanding from superiors are important resources in a Western context [19]. Hence, leadership quality may be an important work environment resource, which could potentially buffer detrimental effects of emotional demands on employee mental health. Such buffering would be in line with previous research showing that positive leader behaviours, such as support, feedback, and trust, are associated with better employee well-being and help employees cope with stress [20,21]. The potential of leaders to aid employee coping may also be inferred from the social support literature. If supportive leadership is considered a type of social support, then previous literature indicates that such behaviour may ameliorate the impact of stressful experiences [22, 23]. According to Thoits [22], buffering by social support may occur because supportive others give active coping assistance or provide emotional sustenance. In a work context, the leader likely has previous experience with the demands faced by the employee and could be considered an experientially similar other. Such individuals may offer emotional sustenance in terms of empathic understanding, acceptance of ventilation, and validation of feelings and concerns [22]. They may also be particularly suited for active coping assistance such as threat re-appraisal or offering of information and advice [22]. Finally, they may be a source of social comparison, offering a role model in dealing with the situation [22].

This study combines questionnaire and register data from two representative cohorts from Denmark and
Sweden, respectively. The aim of the study was to examine whether the association between emotional demands and common mental disorders can be modified by good leadership. Specifically, we hypothesise that the effect of emotional demands on incident antidepressant treatmentas an indicator of common mental disorder-is buffered by good leadership quality, i.e. that the joint effect of these two factors is less than additive. We further explore whether the associations are similar in these two Scandinavian countries.

\section{Methods}

Study design

This study uses data from two representative Scandinavian cohort studies, the Danish Work Environment Cohort Study (DWECS), and the Swedish Longitudinal Occupational Survey of Health (SLOSH). From these multi-wave studies we used DWECS 2005 and SLOSH 2006 because they were collected at a similar time. The questionnaire data were linked with national registers on medication purchases [24]. This study was conducted in accordance with the Helsinki declaration and all individuals gave informed consent to participate in the respective studies by responding to the interview or questionnaire. SLOSH has been approved by the regional ethics board. DWECS has been approved by the Danish Data Protection Agency, but approval from the Danish National Committee on Biomedical Research Ethics is not required for Danish questionnaire- and register-based studies [25].

Details of the included cohort studies are published elsewhere [26-28]. Briefly, DWECS is an on-going cohort study with 5-year follow-ups since 1990. At each wave, the cohort is supplemented to ensure representativeness of the Danish working population. Data for DWECS 2005 were collected during October 2005-May 2006. There were 19,855 eligible participants, of whom $12,413(62.5 \%)$ responded. Of these individuals, 8,064 individuals were gainfully employed, aged 20-59 years, and had full information on personal identification number. The age range was chosen for similarity to SLOSH, which included only individuals 20 years or older, and to include individuals within the average working age ( $<60$ years).

SLOSH is an on-going cohort study that started as a follow-up of individuals from the Swedish Work Environment Survey (SWES) from 2003 to 2007. Respondents to SWES, largely representative of Swedish citizens in gainful employment aged 16-64, were invited to participate in SLOSH. Data for SLOSH were collected during March-May 2006 by inviting the 9,154 eligible participants in SWES 2003, of which 5,985 (65\%) responded. Of 


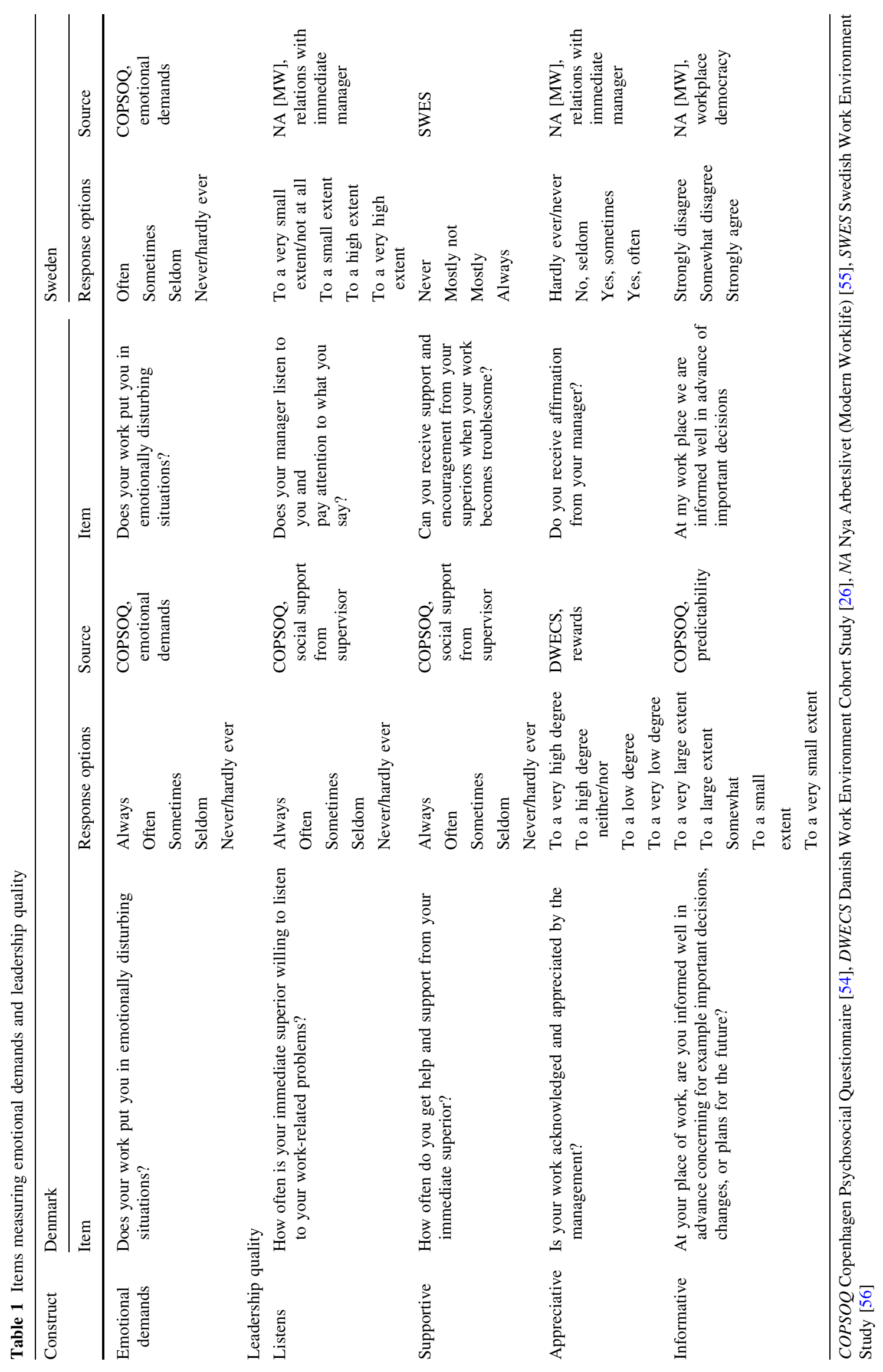


these individuals, 4,351 were gainfully employed (30\% or more on average during the past 3 months) and aged 20-59 years.

\section{Measuring antidepressant treatment}

Antidepressant treatment was measured through national registers on prescription medication purchases, namely the Danish register of medicinal product statistics and the Swedish prescribed drug register [24]. These registers contain all purchases of prescription medications at pharmacies in Denmark since 1995 and Sweden since July 2005. For the present analyses we included Danish data from January 2005 to December 2008 and Swedish data from July 2005 to April 2009. To ensure a prospective analysis on incident episodes of antidepressant treatment, we excluded individuals with any purchase of antidepressants 8.7 months (263 days) before baseline. Time of follow-up was 2.6 years (960 days). The periods for followup and exclusion of prevalent cases were chosen because they were the maximum available for both cohorts.

\section{Measuring emotional demands and leadership quality}

The items used to measure emotional demands at work and leadership quality are presented in Table 1. Emotional demands were assessed in both studies using an item from the Copenhagen Psychosocial Questionnaire (COPSOQ) [29]. To assess leadership quality we constructed a fouritem scale measuring whether the manager listens is supportive, appreciative, and informative. The scales' dimensions and items were chosen partly for commonality between the two cohorts.

We dichotomized emotional demands by defining the responses Sometimes, Often, and Always as high emotional demands. This categorization was based on the distribution of the respondents in the two samples, as the chosen cut off point resulted in about half of the respondents being defined as having high emotional demands. As the samples were nationally representative, we considered an approximate median split a meaningful way of distinguishing high and low levels of emotional demands. Based on the leadership items a composite mean score ranging from 0 through 100 was constructed. This scale was dichotomised at the cohort specific median to define good versus poor quality of leadership.

\section{Covariates}

We included sex and age from the Danish Civil Registration system [30] for DWECS and from self-report for SLOSH. Income was obtained from Statistics Denmark and Sweden, and deaths from the Danish and Swedish
Registers of causes of deaths. We assessed education by register data in DWECS [31] and by self-report in SLOSH, and categorised the variable into $\leq 9,10-11,12,13-14$, and $\geq 15$ years of schooling. We further included self-reported data on marital status (living with a partner or spouse, yes/ no), employment status (part-time/full-time), and mental health at baseline. Part-time work was defined as working $<37 \mathrm{~h}$ in DWECS and $<37$ or $40 \mathrm{~h}$ in SLOSH, depending on occupation.

In DWECS, mental health at baseline was assessed by the five-item Mental Health Inventory (MHI-5) from the Short Form 36 questionnaire [32]. In SLOSH, mental health was assessed by six questions from the (Hopkins) Symptom Checklist 90 (SCL-90) [33]. Scales for mental health were derived as the mean value of the items. Individuals with poor mental health at baseline, defined as MHI-5 $\leq 52$ (scored from 0 to 100 ) or SCL $\geq 3.75$ (scored from 1 to 5 , corresponding to a summary score of $\geq 17$ on a scale from 0 to 24 and about $5 \%$ of the populations), were excluded from the analyses to limit reverse causality. Such reverse causality might occur if individuals with preexisting poor mental health at baseline were also more likely to experience their work as emotionally demanding.

For the sensitivity analyses we further included occupation according to the major groupings of the International Standard Classification of Occupations from 1988 [34]: (0) armed forces, (1) legislators, senior officials, and managers, (2) professionals, (3) clerks, (4) service workers and shop and market sales workers, (5) skilled agricultural and fishery workers, (6) craft and related trades workers, (7) plant and machine operators and assemblers, and (8) elementary occupations.

\section{Study population}

\section{DWECS 2005}

There were 8,064 gainfully employed DWECS participants aged 20-59 years. We excluded 696 individuals who were self-employed, as quality of leadership was not relevant for this group. Further, we excluded 319 individuals with previous purchases of antidepressants, 336 individuals with poor self-reported mental health at baseline, and 623 individuals with missing data on covariates. The final study sample included 6,096 DWECS participants.

\section{SLOSH 2006}

There were 4,318 gainfully employed SLOSH participants aged 20-59 years. After excluding 244 self-employed individuals, we excluded 248 individuals with previous purchases of antidepressants, 183 with poor self-reported 
mental health at baseline, and 232 with missing data on covariates. The final study sample included 3,411 SLOSH participants.

\section{Statistical analyses}

Using Cox proportional hazards regression we examined relative hazard rates [i.e. hazard ratios (HR)] of entering antidepressant treatment during 2.6 years (960 days) of follow-up. Participants were followed in the registers until first purchase of antidepressants, death, or end of followup, whichever came first. Analyses controlled for sex, age, marital status, education, income, and employment status. These potential confounders were chosen a priori as they have been associated with common mental disorder [3537] and could be associated with the examined exposures.

The proportional hazards assumption was tested visually by inspecting the cohort-specific log-log survival plots. Following Rothman [38], we examined joint effects of emotional demands and good leadership by categorising respondents in four groups according to their exposure to these two factors. Both emotional demands and leadership quality were dichotomised and the group with low emotional demands and poor leadership used as reference. We examined interaction as departure from additivity using Rothman's synergy index [38]. A synergy index smaller than one indicates that the joint effect is less than additive (antagonistic), suggesting that good leadership buffers the effect of emotional demands on antidepressant treatment. The $95 \%$ confidence interval for the synergy index was constructed according to Hosmer and Lemeshow [39].

Country-specific risk estimates and standard errors were calculated using SAS version 9.2 (SAS Institute, Cary, NC, USA). Estimates were pooled using inverse variance weighted random effects meta analysis in $\mathrm{R}$ (version 2.10, http://www.rproject.org), applying the meta package [40]. The random effects estimate was based on the DerSimonian and Laird estimator [41], and heterogeneity between the country-specific risks estimates was assessed by Cochran's $Q$ test. In case of statistically significant heterogeneity $(p<0.10)$ the degree of heterogeneity was assessed by $I^{2}[42]$.

\section{Sensitivity analyses}

To assess the robustness of the findings we conducted five sensitivity analyses: (1) examining whether findings were similar for men and women; (2) adjusting the main effects of emotional demands and leadership quality on antidepressants for baseline mental health. This adjustment assessed confounding of the associations by negative affect at baseline and potential differential misclassification of the self-reported work environment; (3) adjusting for occupation to assess confounding by occupation-related treatment-seeking behaviours; (4) examining the countryspecific risk estimates for the joint effects of emotional demands and quality of leadership on antidepressants. This analysis assessed more qualitatively any differences between the countries; and (5) examining the influence of the cut-off point for good leadership and emotional demands, by defining good leadership as the best quartile instead of the best half and high emotional demands as those reporting "often" or more frequent.

\section{Results}

Table 2 shows the characteristics of the study population, and the number of individuals entering antidepressant treatment in relation to these characteristics.

Table 3 shows the main effects of emotional demands and quality of leadership on antidepressant treatment. Individuals with high emotional demands at work had an increased risk of entering antidepressant treatment with a pooled hazard ratio of 1.73 (95\% CI 1.41-2.13). Quality of leadership was not associated with entering antidepressant treatment.

Table 4 shows the joint effects of emotional demands and quality of leadership on antidepressant treatment. The hazard ratio for high emotional demands and poor leadership was 1.84 (95\% CI 1.32-2.57), whereas the hazard ratio for high emotional demands in combination with good leadership was 1.70 (95\% CI 1.25-2.31). The synergy index was 0.66 (95\% CI 0.34-1.28).

\section{Sensitivity analyses}

The findings were similar for men and women, with pooled synergy indices of 0.74 and 0.83 , respectively. The risk estimates for the effects of emotional demands was somewhat attenuated with adjustment for baseline mental health but remained statistically significantly elevated $(\mathrm{HR}=1.49,95 \%$ CI 1.21-1.84, with $p=0.91$ for heterogeneity). For quality of leadership, the hazard ratio after adjustment for baseline mental health was 1.17 (95\% CI $0.95-1.43$ ) with $p=0.91$ for heterogeneity.

Results were similar after adjustment for occupational group, with hazard ratios of 1.75 (95\% CI 1.41-2.17) with $p=0.54$ for heterogeneity for emotional demands and 1.03 (95\% CI $0.85-1.25$ ) with $p=0.51$ for quality of leadership.

The country-specific estimates for the joint effects of emotional demands and quality of leadership on antidepressant treatment are shown in Table 5. The Danish risk estimate for high emotional demands and poor leadership was 2.11 (95\% CI 1.47-3.01), whereas the risk estimate for high emotional demands and good leadership was 1.86 
Table 2 Sample characteristics and caseness of antidepressant treatment in Denmark and Sweden

\begin{tabular}{|c|c|c|c|c|c|c|}
\hline & \multicolumn{2}{|l|}{ Denmark } & \multicolumn{2}{|l|}{ Sweden } & \multicolumn{2}{|l|}{ Pooled } \\
\hline & $n(\%)$ & Cases $(\%)$ & $n(\%)$ & Cases $(\%)$ & $\mathrm{n}(\%)$ & Cases $(\%)$ \\
\hline Total & 6,096 & $266(4.4)$ & 3,411 & $141(4.1)$ & 9,507 & $407(4.3)$ \\
\hline \multicolumn{7}{|c|}{ Emotional demands and leadership } \\
\hline \multicolumn{7}{|c|}{ High emotional demands } \\
\hline Good leadership & $1,098(18.0)$ & $58(5.3)$ & $874(25.6)$ & $51(5.8)$ & $1,972(20.7)$ & $109(5.5)$ \\
\hline Poor leadership & $1,595(26.2)$ & $94(5.6)$ & $781(22.9)$ & $42(5.4)$ & $2,376(25.0)$ & $136(5.7)$ \\
\hline \multicolumn{7}{|l|}{ Low emotional demands } \\
\hline Good leadership & $1,805(29.6)$ & $67(3.7)$ & $920(27.0)$ & $22(2.4)$ & $2,725(28.7)$ & $89(3.3)$ \\
\hline Poor leadership & $1,598(26.2)$ & $47(2.9)$ & $836(24.5)$ & $26(3.1)$ & $2,434(25.6)$ & $73(3.0)$ \\
\hline \multicolumn{7}{|l|}{ Sex } \\
\hline Women & $3,147(51.6)$ & $156(5.0)$ & $1,786(52.4)$ & $105(5.9)$ & 4,933 (51.9) & $261(5.3)$ \\
\hline Men & $2,949(48.4)$ & $110(3.7)$ & $1,625(47.6)$ & $36(2.2)$ & $4,574(48.1)$ & $146(3.2)$ \\
\hline \multicolumn{7}{|l|}{ Marital status } \\
\hline Married/cohabiting & $4,944(81.1)$ & $214(4.3)$ & $2,641(77.4)$ & $106(4.0)$ & $7,585(79.8)$ & $320(4.2)$ \\
\hline Not Married/cohabiting & $1,152(18.9)$ & $52(4.5)$ & $770(22.6)$ & $35(4.6)$ & $1,922(20.2)$ & $87(4.5)$ \\
\hline \multicolumn{7}{|l|}{ Age (years) } \\
\hline $20-29$ & $701(11.5)$ & $19(2.7)$ & $246(7.2)$ & $6(2.4)$ & $947(10.0)$ & $25(2.6)$ \\
\hline $30-39$ & $1,716(28.2)$ & $73(4.3)$ & $831(24.4)$ & $30(3.6)$ & $2,547(26.8)$ & $103(4.0)$ \\
\hline $40-49$ & $1,923(31.6)$ & $92(4.8)$ & $1,068(31.3)$ & $53(5.0)$ & $2,991(31.5)$ & $145(4.8)$ \\
\hline $50-59$ & $1,756(28.8)$ & $82(4.7)$ & $1,266(37.1)$ & $52(4.1)$ & $3,022(31.8)$ & $134(4.4)$ \\
\hline \multicolumn{7}{|l|}{ Education } \\
\hline$<10$ years & $509(8.4)$ & $26(5.1)$ & $473(13.9)$ & $13(2.8)$ & $982(10.3)$ & $39(4.0)$ \\
\hline $10-11$ years & $671(11.0)$ & $49(7.3)$ & $798(23.4)$ & $33(4.1)$ & $1,469(15.5)$ & $82(5.6)$ \\
\hline 12 years & $826(13.6)$ & $36(4.4)$ & $758(22.2)$ & $29(3.8)$ & $1,584(16.7)$ & $65(4.1)$ \\
\hline 13-14 years & $2,426(39.8)$ & $89(3.7)$ & $486(14.3)$ & $29(6.0)$ & $2,912(30.6)$ & $118(4.1)$ \\
\hline at least 15 years & $1,664(27.3)$ & $66(4.0)$ & $896(26.3)$ & $37(4.1)$ & $2,560(26.9)$ & $103(4.0)$ \\
\hline \multicolumn{7}{|l|}{ Wage } \\
\hline Quartile 1 (lowest) & $1,524(25.0)$ & $82(5.4)$ & $840(24.6)$ & $58(6.9)$ & $2,364(24.9)$ & $140(5.9)$ \\
\hline Quartile 2 & $1,524(25.0)$ & $75(4.9)$ & $851(25.0)$ & $36(4.2)$ & $2,375(25.0)$ & $111(4.7)$ \\
\hline Quartile 3 & $1,524(25.0)$ & $62(4.1)$ & 849 (24.9) & $25(2.9)$ & $2,373(25.0)$ & $87(5.7)$ \\
\hline Quartile 4 (highest) & $1,524(25.0)$ & $47(3.1)$ & $871(25.5)$ & $22(2.5)$ & $2,395(25.2)$ & 69 (2.9) \\
\hline \multicolumn{7}{|l|}{ Full-time/part-time work } \\
\hline Working part-time & $1,433(23.5)$ & $67(4.7)$ & $590(17.3)$ & $33(5.6)$ & $2,023(21.3)$ & $100(4.9)$ \\
\hline Working full-time & $4,663(76.5)$ & $199(4.3)$ & $2,821(82.7)$ & $108(3.8)$ & 7,484 (78.7) & $307(4.1)$ \\
\hline
\end{tabular}

Table 3 Incident antidepressant treatment in relation to main effects of emotional demands and quality of leadership

\begin{tabular}{llll}
\hline & $\mathrm{HR}^{\mathrm{a}}$ & $95 \% \mathrm{CI}$ & $\begin{array}{l}p \text { value for } \\
\text { heterogeneity }(Q \text { test) }\end{array}$ \\
\hline $\begin{array}{c}\text { Emotional demands } \\
\text { (high vs. low) }\end{array}$ & 1.73 & $1.41-2.13$ & 0.84 \\
$\begin{array}{c}\text { Leadership (good vs. } \\
\text { poor) }\end{array}$ & 0.94 & $0.78-1.15$ & 0.69 \\
\hline
\end{tabular}

$H R$ hazard ratio, $95 \% C I$ confidence interval

${ }^{\text {a }}$ Pooled estimate, adjusted for sex, age, marital status, education, wage, employment status (part-time vs. full-time)
(95\% CI 1.26-2.76). The synergy index was 0.63 (95\% CI $0.32-1.24)$. The Swedish risk estimates for high emotional demands were similar in the presence of poor and good quality of leadership, with HRs of 1.49 (95\% CI 0.92-2.41) and 1.47 (95\% CI 0.90-2.41), respectively. The Swedish synergy index was $1.83 \quad(95 \%$ CI 0.08-42.10), thus pointing in the opposite direction of the Danish index. The difference between the two synergy indices was not statistically significant.

When changing the cut-off points and defining good leadership as the best quartile and high emotional demands to those responding "often" or always, some indication of 
Table 4 Incident antidepressant-use in relation to joint distribution of emotional demands and quality of leadership

\begin{tabular}{|c|c|c|c|c|c|}
\hline & $\mathrm{HR}^{\mathrm{a}}$ & $95 \% \mathrm{CI}$ & Synergy index & $95 \% \mathrm{CI}$ & $p$ value for heterogeneity ( $Q$ test) \\
\hline \multicolumn{6}{|c|}{ High emotional demands } \\
\hline Good leadership & 1.70 & $1.25-2.31$ & - & - & 0.50 \\
\hline Poor leadership & 1.84 & $1.32-2.57$ & - & - & 0.26 \\
\hline \multicolumn{6}{|c|}{ Low emotional demands } \\
\hline Good leadership & 1.04 & $0.64-1.68$ & - & - & 0.16 \\
\hline \multirow[t]{2}{*}{ Poor leadership } & 1 (ref) & - & - & - & - \\
\hline & & & 0.66 & $0.34-1.28$ & 0.51 \\
\hline
\end{tabular}

HR Hazard ratio, $95 \%$ CI confidence interval

${ }^{a}$ Pooled estimate, adjusted for sex, age, marital status, education, wage, employment status (part-time vs. full-time)

Table 5 Country-specific estimates for incident antidepressant-use in relation to joint distribution of emotional demands and quality of leadership

$H R$ hazard ratio, $95 \% C I$ confidence interval

a Adjusted for sex, age, marital status, education, wage, employment status (part-time vs. full-time)

\begin{tabular}{|c|c|c|c|c|c|c|c|c|}
\hline & \multicolumn{4}{|c|}{ Danish estimates } & \multicolumn{4}{|c|}{ Swedish estimates } \\
\hline & $\mathrm{HR}^{\mathrm{a}}$ & $95 \% \mathrm{CI}$ & $\begin{array}{l}\text { Synergy } \\
\text { index }\end{array}$ & $95 \% \mathrm{CI}$ & $\mathrm{HR}^{\mathrm{a}}$ & $95 \% \mathrm{CI}$ & $\begin{array}{l}\text { Synergy } \\
\text { index }\end{array}$ & $95 \% \mathrm{CI}$ \\
\hline \multicolumn{9}{|c|}{ High emotional demands } \\
\hline $\begin{array}{l}\text { Good } \\
\text { leadership }\end{array}$ & 1.86 & $1.26-2.76$ & - & - & 1.47 & $0.90-2.41$ & - & - \\
\hline $\begin{array}{l}\text { Poor } \\
\text { leadership }\end{array}$ & 2.11 & $1.47-3.01$ & - & - & 1.49 & $0.92-2.41$ & - & - \\
\hline \multicolumn{9}{|c|}{ Low emotional demands } \\
\hline $\begin{array}{l}\text { Good } \\
\text { leadership }\end{array}$ & 1.27 & $0.87-1.84$ & - & - & 0.77 & $0.43-1.37$ & - & - \\
\hline \multirow[t]{2}{*}{$\begin{array}{l}\text { Poor } \\
\text { leadership }\end{array}$} & 1 (ref) & - & - & - & 1 (ref) & - & - & - \\
\hline & & & 0.63 & $0.32-1.24$ & & & 1.83 & $0.08-42.10$ \\
\hline
\end{tabular}

buffering was seen in the Danish data: the HR for high emotional demands with poor leadership was $1.58(95 \%$ CI 1.10-2.25), whereas the HR with good leadership was 1.03 (95\% CI 0.72-1.46). However, the Swedish results pointed in the opposite direction, with a HR for high emotional demands and poor leadership of 1.17 (95\% CI 0.71-1.93) and for high emotional demands and good leadership of 1.41 (95\% CI 0.86-2.31). It should be noted, though, that the numbers of respondents now classified as having high emotional demands and good leadership were small; there were 139 (6 cases) and 95 respondents (7 cases) in this category in DWECS and SLOSH, respectively.

\section{Discussion}

This study examined whether good leadership buffers the effects of emotional demands on common mental disorders, as indicated by antidepressant treatment. The results, however, indicate that any buffering by good leadership is modest; the risk of entering antidepressant treatment was increased for employees with high emotional demands, whether leadership was poor 1.84 (95\% CI 1.32-2.57) or good 1.70 (95\% CI 1.25-2.31). Also, the synergy index was not statistically significantly different from 1 , although this could be due to lacking statistical power. The findings were unchanged when defining only the best quartile as good leadership, so the patterns are unlikely to be explained by the dichotomization of leadership quality. The country-specific estimates for Denmark and Sweden showed somewhat differing patterns with some indication toward buffering in the Danish data; antidepressant treatment was, however, still substantially increased for Danish employees with high emotional demands and good leadership, indicating that any preventive effects of leadership may be modest.

To the best of our knowledge, this is the first study to examine the buffering effect of leadership quality on the association between emotional demands at work and antidepressants. The lack of buffering contrasts the conservation of resources theory [19], which states that high availability of resources reduces the risk that expenditure of resources results in adverse health outcomes. The measure we used for leadership quality was, however, partly based on the availability of similar items in the two 
studies. Hence it was not a validated scale, and may not have captured the most important aspects of leadership quality satisfactorily, possibly explaining the lack of main and buffering effects of this construct in the present analyses. Another limitation of our study is that we measured emotional demands using a single item, rather than the full scale-again this operationalization reflected data availability. Furthermore, the general population study sample we applied may not have provided sufficient exposure contrast on leadership quality to demonstrate its full buffering potential, given the distribution of this construct in the sample, with most respondents clustered around average-to-good levels. The issues concerning the exposure contrast of both emotional demands and leadership were not improved by their dichotomizations, which were unfortunately required to examine buffering as departure from additivity. It seems that further studies examining occupation- and/or workplace-specific samples may be needed on this issue.

In relation to the measurement of leadership, the applied scale largely measured supportive leadership, and indeed two of the items in the Danish data were previously used in a scale on supervisor social support. Although we had reason to expect that social support could buffer the consequences of stressors [22], it is possible that social support from colleagues may be more important than social support from supervisors, in the context of emotional demands. Whilst we could not examine the relevance of colleague social support in the present study, due to data availability, this issue certainly warrant further scrutiny.

Although we did not find substantial buffering of the association between emotional demands and antidepressants by quality of leadership, this should not be interpreted as a negation of the importance of ensuring good leadership at work; previous research indicates that managers who provide information, clarity, support, and inspiration are favourable to employee health [43, 44]. Better mental health has also been associated with transformational leadership, i.e. leadership characterised by idealised influence, inspirational motivation, intellectual stimulation, and individualised consideration [45]. Furthermore, employee psychological well-being has been found increased with leaders who provide feedback, support, communication, commitment to quality, fairness, integrity/respect, participation and empowerment, and value diversity [20]. Reduced employee psychological well-being, conversely, has been associated with leadership that is experienced as autocratic, malevolent, and self-centred [46]. Additionally, longitudinal interventionbased evidence suggests that strengthening the leaders' abilities to intervene in conflict-ridden interpersonal situations leads to improved employee psychological wellbeing [47]. Some, but not all, of these qualities were measured in the present study, and the applied leadership measure possibly explains the lacking main effect of leadership on antidepressants.

Alternatively, the lack of buffering may be explained by opposite effects of leadership on mental health and treatment-seeking in individuals with emotionally demanding work. If good leaders are associated not only with better employee mental health but also more supportive of treatment seeking, these effects may balance each other out, when examining antidepressant treatment.

It is, however, also possible that predictors of clinically significant common mental disorder differ from those of self-reported mental well-being or psychological distressthe outcomes most often previously associated with leadership quality. Consequently, it seems that more work is needed to identify health promoting leadership aspects and their effects [43].

Emotional demands at work have previously been associated not only with antidepressant treatment $[15,16]$ but also other mental health indicators, including hospitalization with depression [14] and depressive symptoms $[12,13]$. It is unclear, though, if there is a causal effect of emotionally demanding work on mental health. The association may be confounded by poor baseline mental health possibly increasing the risks of experiencing high emotional demands at work and developing common mental disorder. The results in this article, however, suggest that this may not be a primary source of bias. First, emotional demands were still associated with antidepressant treatment after adjustment for baseline mental health. Second, if poor baseline mental health influences how employees experience their work, this would likely influence both the experience of high emotional demands and poor leadership quality. Hence, if baseline mental health were the primary force driving the associations between work environment and common mental disorders, we would not expect an increased risk of antidepressant treatment in the group experiencing high emotional demands but good quality of leadership. Consequently, the observed pattern with increased antidepressant treatment in employees with high emotional demands regardless of leadership quality, suggests that baseline mental health differences are not the primary factor driving the association. This pattern, would, however, also be consistent with a selection of individuals particularly vulnerable to common mental health problems into emotionally demanding occupations, as indicated previously for Danish eldercare workers [48]. Such selection could, however, not be partialled out given the available data. Hence, the causality of the association between emotional demands and mental health remains uncertain.

Another potential confounder when using antidepressants as an indicator for common mental disorders is treatmentseeking behaviour [49]. Emotional demands are high in 
human service occupations (e.g., nursing, teaching) [15]. If these employees are also more likely to seek medical help when suffering from common mental disorder, this would bias the observed associations upwards. The sensitivity analysis adjusting for occupational group did, however, not change results-suggesting that occupation is not a major confounder for the results of this article. It should be noted, though, that the ISCO-88 major grouping is somewhat coarse and may not have been sufficiently nuanced to fully account for any occupational differences.

This study used national data on purchases of antidepressant medications, as an indicator of clinically significant common mental disorder. This allowed a 2.6-year dayto-day follow-up of all participants from the two studies and avoided selective participation at follow-up. The outcome of antidepressants treatment as an indicator for common mental disorder should, however, be interpreted cautiously. Antidepressants are used for various disorders, not only including depressive, anxiety, and sleep disorders, but also incontinence, bulimia, headache, and psychotic disorders $[50,51]$. As most antidepressants are, nevertheless, prescribed for common mental disorders [51-53], antidepressants seem a valid measure of common mental disorder in general, but specific disorders cannot be disentangled. Unfortunately, the treatment indication was unavailable in the present study. Hence, the association between emotional demands and common mental disorder should be examined further using more specific outcome measures that might point to the exact nature of any mental health consequences.

To conclude, we found that high emotional demands at work predicted entering antidepressant treatment and that good leadership did not convincingly prevent this effect. Further research is needed to identify possible buffers of effects of emotional demands at work on employee mental health.

Acknowledgments This work was supported by grants from the Danish Working Environment Research Fund [grant number 03-2008-09] and the Swedish Council for Working Life and Social Research (FAS) [Grant Number 2008-1103, 2005-0734], who also support research based at Stress Research Institute through the Stockholm Stress Centre of excellence [Grant Number 2009-1758].

Conflict of interest On behalf of all authors, the corresponding author states that there is no conflict of interest.

Open Access This article is distributed under the terms of the Creative Commons Attribution License which permits any use, distribution, and reproduction in any medium, provided the original author(s) and the source are credited.

\section{References}

1. Lopez AD, Mathers CD, Ezzati M, Jamison DT, Murray CJL (2006) Global and regional burden of disease and risk factors,
2001: systematic analysis of population health data. Lancet 367:1747-1757

2. Goldberg DP, Goodyer IM (2005) The origins and course of common mental disorders. Routledge, Hove

3. Stansfeld S, Candy B (2006) Psychosocial work environment and mental health - a meta-analytic review. Scand J Work Environ Health 32:443-62. http://www.ncbi.nlm.nih.gov/entrez/query. fcgi? $\mathrm{cmd}=$ Retrieve $\& \mathrm{db}=$ PubMed $\&$ dopt $=$ Citation $\&$ list_uids $=171$ 73201

4. Bonde JPE (2008) Psychosocial factors at work and risk of depression: a systematic review of the epidemiological evidence. Occup Environ Med 65:438-445

5. Netterstrøm B, Conrad N, Bech P, Fink P, Olsen O, Rugulies R et al (2008) The relation between work-related psychosocial factors and the development of depression. Epidemiol Rev 30:18-32 (PM:18587142)

6. Siegrist J (2008) Chronic psychosocial stress at work and risk of depression: evidence from prospective studies. Eur Arch Psychiatry Clin Neurosci 258:115-119 (ISI:000262752900022)

7. Laaksonen M, Lallukka T, Lahelma E, Partonen T (2011) Working conditions and psychotropic medication: a prospective cohort study. Soc Psychiatry Psychiatr Epidemiol 47:663-670

8. Cohidon C, Gl Santin, Imbernon E, Goldberg M (2010) Working conditions and depressive symptoms in the 2003 decennial health survey: the role of the occupational category. Soc Psychiat Epidemiol 45:1135-1147

9. van Vegchel N, de Jonge J, Söderfeldt M, Dormann C, Schaufeli W (2004) Quantitative versus emotional demands among swedish human service employees: moderating effects of job control and social support. Int J Stress Manag 11:21-40

10. Burr H, Albertsen K, Rugulies R, Hannerz H (2010) Do dimensions from the Copenhagen Psychosocial Questionnaire predict vitality and mental health over and above the job strain and effort-reward imbalance models? Scand J Public Health 38:59-68. doi:(ISI:000274117100008)

11. Bültmann U, Kant IJ, Schröer CAP, Kasl SV (2002) The relationship between psychosocial work characteristics and fatigue and psychological distress. Int Arch Occup Environ Health 75:259-266

12. Andrea H, Bültmann U, Beurskens AJHM, Swaen GMH, van Schayck CP, Kant IJ (2004) Anxiety and depression in the working population using the HAD Scale. Soc Psychiatry Psychiatr Epidemiol 39:637-646

13. Kim I, Noh S, Muntaner C (2013) Emotional demands and the risks of depression among homecare workers in the USA. Int Arch Occup Environ Health 86:635-644

14. Wieclaw J, Agerbo E, Mortensen PB, Burr H, Tüchsen F, Bonde JP (2008) Psychosocial working conditions and the risk of depression and anxiety disorders in the Danish workforce. BMC Public Health 8:280

15. Madsen IEH, Diderichsen F, Burr H, Rugulies R (2010) Personrelated work and incident use of antidepressants: relations and mediating factors from the Danish work environment cohort study. Scand J Work Environ Health 36:435-444 (PM:20517584)

16. Magnusson Hanson LL, Madsen IEH, Westerlund H, Theorell T, Burr H, Rugulies R (2013) Antidepressant use and associations with psychosocial work characteristics. A comparative study of Swedish and Danish gainfully employed. J Affect Disord 149: $38-45$

17. Söderfeldt B, Söderfeldt M, Muntaner C, O'Campo P, Warg LE, Ohlson CG (1996) Psychosocial work environment in human service organizations: a conceptual analysis and development of the demand-control model. Soc Sci Med 42:1217-1226 (PM:8733192)

18. Hasenfeld Y, English RA (1974) Human service organizations: a conceptual overview. In: Hasenfeld Y, English RA (eds) Human 
service organizations: a book of readings. University of Michigan Press, Ann Arbor, pp 1-24

19. Hobfoll S (2001) The influence of culture, community, and the nested-self in the stress process: advancing conservation of resources theory. Appl Psychol: Int Rev 50:337-421

20. van Dierendonck D, Haynes C, Borrill C, Stride C (2004) Leadership behavior and subordinate well-being. J Occup Health Psychol 9:165-175 (ISI:000235620400005)

21. Skakon J, Nielsen K, Borg V, Guzman J (2010) Are leaders' wellbeing, behaviours and style associated with the affective wellbeing of their employees? A systematic review of three decades of research. Work Stress 24:107-139

22. Thoits PA (2011) Mechanisms linking social ties and support to physical and mental health. J Health Soc Behav 52:145-161

23. Cohen S (2004) Social relationships and health. Am Psychol 59:676-684

24. Furu K, Wettermark B, Andersen M, Martikainen JE, Almarsdottir AB, Sørensen HT (2009) The Nordic countries as a cohort for pharmacoepidemiological research. Basic Clin Pharmacol Toxicol 106:86-94

25. Den Centrale Videnskabsetiske Komité (The Danish National Committee on Biomedical Research). Guidelines about Notification. Den Centrale Videnskabsetiske Komité (The Danish National Committee on Biomedical Research) (2011) 12 June 2012

26. Feveile H, Olsen O, Burr H, Bach E (2007) Danish work environment cohort study 2005: from idea to sampling design. Stat Transit 8:441-458

27. Kinsten A, Magnusson Hanson L, Hyde M, Oxenstierna G, Westerlund H, Theorell T (2007) Swedish Longitudinal Occupational Survey of Health-a nationally representative psychosocial survey of the Swedish working population. Stress Research Institute, Stockholm University, Stockholm, p 321

28. Magnusson Hanson L, Theorell T, Oxenstierna G, Hyde M, Westerlund H (2008) Demand, control and social climate as predictors of emotional exhaustion symptoms in working Swedish men and women. Scand J Public Health 36:737-743. http:// dx.doi.org/10.1177/1403494808090164

29. Kristensen TS, Hannerz H, Høgh A, Borg V (2005) The Copenhagen psychosocial questionnaire-a tool for the assessment and improvement of the psychosocial work environment. Scand J Work Environ Health 31:438-449 (PM:16425585)

30. Pedersen CB (2011) The Danish civil registration system. Scand J Public Health 39:22-25 (ISI:000292984700005)

31. Jensen VM, Rasmussen AW (2011) Danish education registers. Scand J Public Health 39:91-94 (ISI:000292984700023)

32. Bjorner JB, Thunedborg K, Kristensen TS, Modvig J, Bech P (1998) The Danish SF-36 health survey: translation and preliminary validity studies. J Clin Epidemiol 51:991-9. http://www. ncbi.nlm.nih.gov/entrez/query.fcgi? $\mathrm{cmd}=$ Retrieve $\& \mathrm{db}=$ PubMed $\&$ dopt $=$ Citation\&list_uids $=9817117$

33. Magnusson Hanson L, Theorell T, Bech P, Rugulies R, Burr H, Hyde $M$ et al (2009) Psychosocial working conditions and depressive symptoms among Swedish employees. Int Arch Occup Environ Health 82:951-960

34. International Labour Organization (ILO) (2004) ISCO-88: major, sub-major, minor and unit group titles. International Labour Organization (ILO), 25 January 2011

35. Harris T (2001) Recent developments in understanding the psychosocial aspects of depression. Br Med Bull 57:17-32. http:// bmb.oxfordjournals.org/cgi/content/abstract/57/1/17

36. Olsen LR, Mortensen EL, Bech P (2004) Prevalence of major depression and stress indicators in the Danish general population. Acta Psychiatr Scand 109:96-103. http://search.ebscohost. com/login.aspx ?direct $=$ true $\& \mathrm{db}=\mathrm{aph} \& \mathrm{AN}=11956544 \&$ site $=$ ehost live
37. Simon RW (2002) Revisiting the relationships among gender, marital status, and mental health. AJS 107:1065-1096 (ISI:000176739000005)

38. Rothman KJ (1976) The estimation of synergy or antagonism. Am J Epidemiol 103:506-511

39. Hosmer DW, Lemeshow S (1992) Confidence-interval estimation of interaction. Epidemiology 3:452-456

40. Schwarzer, Guido. Package 'meta'. The R Foundation for Statistical Computing. 2012. 9 May 2012

41. DerSimonian R, Laird N (1986) Meta-analysis in clinical trials. Control Clin Trials 7:177-88. http://www.ncbi.nlm.nih.gov/htbinpost/Entrez/query?db=m\&form $=6 \& d o p t=r \& u i d=0003802833$

42. Higgins JPT, Thompson SG, Deeks JJ, Altman DG (2003) Measuring inconsistency in meta-analyses. BMJ 327:557-560 (ISI:000185283700028)

43. Nyberg A (2009) The impact of managerial leadership on stress and health among employees. Karolinska Institutet, Stockholm

44. Nyberg A, Alfredsson L, Theorell T, Westerlund H, Vahtera J, Kivimaki M (2009) Managerial leadership and ischaemic heart disease among employees: the Swedish WOLF study. Occup Environ Med 66:51-55 (ISI:000261833400010)

45. Arnold KA, Turner N, Barling J, Kelloway EK, Mckee MC (2007) Transformational leadership and psychological wellbeing: the mediating role of meaningful work. J Occup Health Psychol 12:193-203

46. Nyberg A, Holmberg I, Bernin P, Alderling M, Akerblom S, Widerszal-Bazyl M et al (2011) Destructive managerial leadership and psychological well-being among employees in Swedish, Polish, and Italian hotels. Work 39:267-281

47. Romanowska J, Larsson G, Eriksson M, Wikstrom BM, Westerlund H, Theorell T (2011) Health effects on leaders and coworkers of an art-based leadership development program. Psychother Psychosom 80:78-87

48. Madsen IEH, Aust B, Burr H, Carneiro IG, Diderichsen F, Rugulies R (2012) Paid care work and depression: a longitudinal study of antidepressant treatment in female eldercare workers before and after entering their profession. Depress Anxiety 29:605-613

49. Thielen K, Nygaard E, Rugulies R, Diderichsen F (2011) Job stress and the use of antidepressant medicine: a 3.5-year followup study among Danish employees. Occup Environ Med 68:205-210

50. Trifirò G, Barbui C, Spina E, Moretti S, Tari M, Alacqua $\mathrm{M}$ et al (2007) Antidepressant drugs: prevalence, incidence and indication of use in general practice of Southern Italy during the years 2003-2004. Pharmacoepidemiol Drug Saf 16:552-559

51. Gardarsdottir H, Heerdink ER, van Dijk L, Egberts ACG (2007) Indications for antidepressant drug prescribing in general practice in the Netherlands. J Affect Disord 98:109-115 (ISI:000244116700011)

52. Mark TL (2010) For what diagnoses are psychotropic medications being prescribed? A nationally representative survey of physicians. Cns Drugs 24:319-326 (ISI:000276820100004)

53. Rosholm JU, Gram LF, Damsbo N, Hallas J (1995) Antidepressant treatment in general-practice-an interview study. Scand J Prim Health Care 13:281-286

54. Kristensen TS, Borg V, Hannerz H (2002) Socioeconomic status and psychosocial work environment: results from a Danish national study. Scand J Public Health Suppl 59:41-48

55. Oxenstierna G, Widmark M, Finnholm K, Elofsson S (2008) A new questionnaire and model for research into the impact of work and the work environment on employee health. Scand J Work Environ Health Suppl 6:150-162

56. Arbetsmiljöverket. Arbetsmiljön 2003 (The Work Environment 2003, report in Swedish) Statistiska centralbyrån (2004). http:// www.scb.se/Pages/PublishingCalendarViewInfo PublObjId=537 